\title{
Principle and Model Block Diagrams of Cd Content Monthly Variation in Surface and Bottom Waters in Central Bay
}

\author{
Dongfang Yang ${ }^{1,2,}$, Dong Yang ${ }^{1}$, Weifeng Ling ${ }^{1}$, Dong Lin ${ }^{1}$, and Haixia $\mathrm{Li}^{1}$ \\ ${ }^{1}$ Accountancy School, Xijing University, Xi' an 710123, China \\ ${ }^{2}$ North China Sea Environmental Monitoring Center, SOA, Qingdao 266033, China
}

\begin{abstract}
According to survey data, in Jiaozhou Bay in 1992, the vertical distribution of Cd content and monthly changes in the surface and the bottom of the central sea area of Jiaozhou Bay were studied, and monthly changes, migration processes and variational principles of the Cd content in surface and bottom water were determined. In May, August, and October, the water body that the main sea current did not pass through were those in the center of the bay. Cd content in central surface water of Jiaozhou Bay was not transported from any source outside the bay from May to October. The results showed that Cd content transported by the main sea current changed from low to high in October, May and August; Cd content transported by the bay current changed from low to high: October, August and May; Cd content in surface water in the bay center changed from low to high in: August, May and October; Cd content in the bottom bay center changed from low to high in May, October and August. Thus, from May to October, monthly changes in these four parts were different. For this reason, the monthly variation principle of Cd content in the surface and bottom waters of the bay was proposed. In addition, the model block diagrams were established to show the change process and principle of $\mathrm{Cd}$ content deposition and migration. The principle shows that the bay current has no direct effect on the surface water in the center of the bay from May to October. However, the bottom water body in the center of Jiaozhou Bay was greatly affected, and the surface water body in the center of Jiaozhou Bay was further affected by the upwelling.
\end{abstract}

\section{Introduction}

Large amounts of cadmium $(\mathrm{Cd})$ were transported into the land, sea and atmosphere by humans, eventually reaching the surface waters of the ocean. Under the action of the current, the $\mathrm{Cd}$ content was continuously transported to various waters through the current. In the process of ocean current transport, $\mathrm{Cd}$ content continuously sank to the seabed, and then was brought to the surface of the ocean through the upwelling [1-10].Therefore, with the aid of the data about $\mathrm{Cd}$ in Jiaozhou Bay in 1992, we study vertical distribution and horizontal distribution of $\mathrm{Cd}$ in surface and bottom waters of the central Jiaozhou Bay, determining horizontal distribution, vertical distribution and migration theory of $\mathrm{Cd}$ content in the surface and bottom water.We also showhorizontal and vertical settlement process of Cd content in Jiaozhou Bay waters, providing a scientific basis for the study of the vertical settlement and horizontal migration of $\mathrm{Cd}$ content in the surface and bottom water.

\section{Water Area, Materials and Methods}

2.1 Natural Environment of Jiaozhou Bay .Jiaozhou Bay lies in the south of the Shandong Peninsula. Its geographical position is between $120^{\circ} 04^{\prime}-120^{\circ} 23^{\prime} \mathrm{E}$ and $35^{\circ} 58^{\prime}-36^{\circ} 18^{\prime} \mathrm{N}$. The boundary is at the junction of Tuan Island and Xuejia Island. Jiaozhou Bay is connected with the Yellow Sea. With an area of about $446 \mathrm{~km} 2$ and an average water depth of about $7 \mathrm{~m}$, it is a typical semi-enclosed bay. There are more than ten rivers entering the sea in Jiaozhou Bay, among which Dagu River and Yang River, Haibo River, Licun River and Loushan River in Qingdao urban area have a large amount of runoff and sand. They are all seasonal because the hydrological characteristics of rivers water show obvious seasonal changes [11, 12]. 


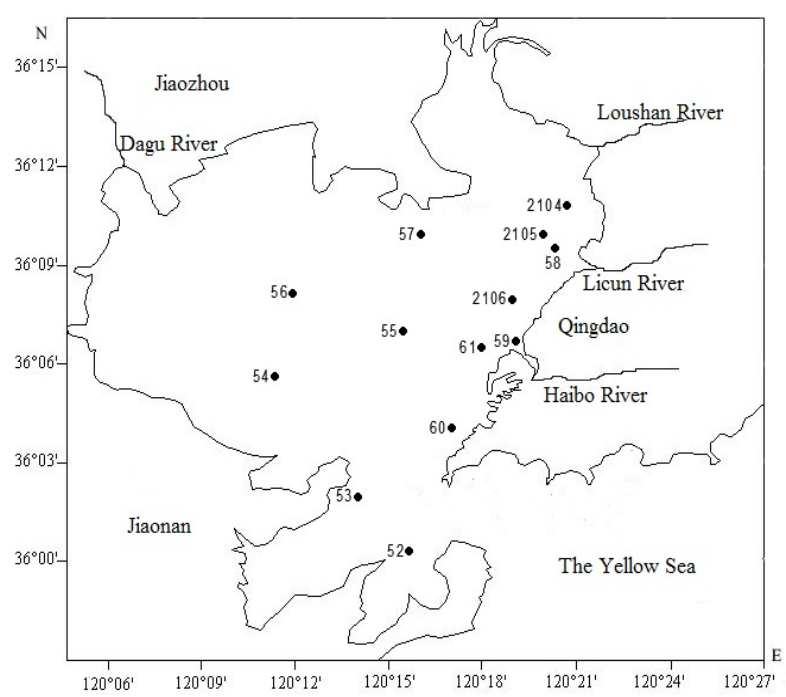

Figure 1 Investigation sites in Jiaozhou Bay

2.2 Materials and Methods. This paper uses survey data about Cd in Jiaozhou Bay in May, August and October 1992, provided by the North China Sea Environmental Monitoring Center. Three water sampling stations were set up in the waters of Jiaozhou Bay: site 52, site 59 and site 60(Figure 1) in May, August and October 1992, according to water depth (When the depth was more than $10 \mathrm{~m}$, we took samples from the surface and bottom. Otherwise, we only took samples from the surface. $\mathrm{Cd}$ in Jiaozhou Bay water body was investigated according to the national standard method stipulated in the Specification for Marine Monitoring (1991) [13].

\section{Results}

3.1 Current Track in the Bay. Jiaozhou Bay is a dustpan - shaped shallow bay. On the whole, it tilts straight and then turns to the east at the bay mouth. It is Shallow in the northwest but deep in the southeast. The main sea current carries matter content into Jiaozhou Bay through the bay mouth. The current follows the inshore waters in the northeast, passes through the southeastern waters of the bay, and moves northeast to the most northeastern waters of the bay, reaching the estuary of Loushan River. Then it turns west and passes through the coastal waters north of the bay. Then it travels to the westernmost northwest waters and reaches the estuary of Dagu River. It then turns south and follows the western inshore waters to the bay mouth (Figure 2). Therefore, the main sea current carries matter content into and around the inshore waters of Jiaozhou Bay.

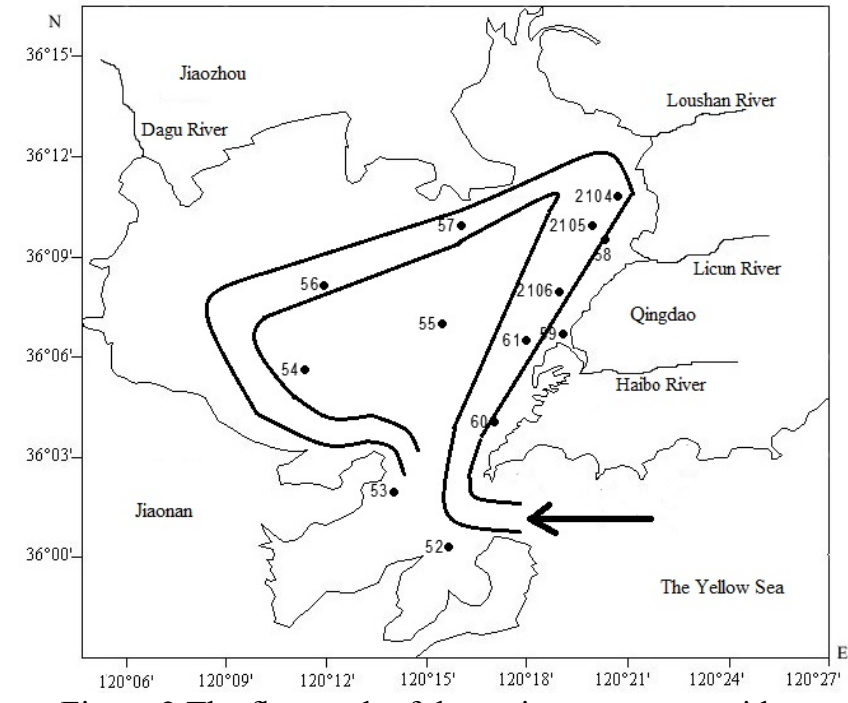

Figure 2 The flow path of the main sea current with matter content in Jiaozhou Bay $(\mu \mathrm{g} / \mathrm{L})$

In May, the $\mathrm{Cd}$ content transported by the main sea current was $0.59 \mu \mathrm{g} / \mathrm{L}$. It in August was $1.11 \mu \mathrm{g} / \mathrm{L}$. In October, it was $0.39 \mu \mathrm{g} / \mathrm{L}$. In conclusion, the change of $\mathrm{Cd}$ content in the main sea current from low to high is October, May and August. In May, August, and October, the waters that the main sea current did not pass through were located at site 55 in the center of the bay. The $\mathrm{Cd}$ content in the central surface water of Jiaozhou Bay was not transported from any source from May to October.

3.2 Changes in the Content Carried by the Bay Current. In May, in the waters near the estuary of the Haibo River, Cd content $1.07 \mu \mathrm{g} / \mathrm{L}$ came from Haibo River. Near the estuary of Licun River, Cd content transported by Licun River was $1.20 \mu \mathrm{g} / \mathrm{L}$. Cd content was $1.16 \mu \mathrm{g} / \mathrm{L}$ in coastal waters of Loushan River estuary, which was transported from the Loushan River. In the northern waters of the bay, $\mathrm{Cd}$ content $1.10 \mu \mathrm{g} / \mathrm{L}$ came from run-off. Near the estuary of Dagu River, Cd content transported by Dagu River was $1.53 \mu \mathrm{g} / \mathrm{L}$. Therefore, the main sea current brought $\mathrm{Cd}$ content into Jiaozhou Bay and surrounded the nearshore waters of the bay. In addition, $\mathrm{Cd}$ content in the bay current ranged from $0.59 \mu \mathrm{g} / \mathrm{L}$ to $1.53 \mu \mathrm{g} / \mathrm{L}$.

In August, $\mathrm{Cd}$ content transported by the main sea current in the bay mouth was $1.11 \mu \mathrm{g} / \mathrm{L}$.Near the estuary of Dagu River, Cd content transported by Dagu River was $0.96 \mu \mathrm{g} / \mathrm{L}$. Therefore, the main sea current brought $\mathrm{Cd}$ content into Jiaozhou Bay and surrounded the nearshore waters of Jiaozhou Bay. Moreover, Cd content in the baycurrentchanged from 0.96 to $1.11 \mu \mathrm{g} / \mathrm{L}$.

In October, the Cd content transported by Licun River in the sea area near the estuary of Licun River was $1.10 \mu \mathrm{g} / \mathrm{L}$. The Cd content near the estuary of Loushan River was $1.04 \mu \mathrm{g} / \mathrm{L}$, which was transported from Loushan River. Therefore, the main sea current brought $\mathrm{Cd}$ content into Jiaozhou Bay and surrounded the nearshore waters. What's more, $\mathrm{Cd}$ content transported by the bay currentvaried from 0.39 to $1.10 \mu \mathrm{g} / \mathrm{L}$. 
3.3 Monthly Variation Process of Cd Content in the Central Waters of the Bay. Cd content in central surface water of Jiaozhou Bay decreased gradually from the low value of $0.44 \mu \mathrm{g} / \mathrm{L}$ in May. In August, Cd content reached a minimum of $0.12 \mu \mathrm{g} / \mathrm{L}$ and then started to rise. In October, Cd content reached a high value of $0.89 \mu \mathrm{g} / \mathrm{L}$.As a result, the monthly change of $\mathrm{Cd}$ content in surface water from low to high was August, May, and October.

Jiaozhou Bay is a shallow bay. The main sea current carried matter content into Jiaozhou Bay and surrounded the inshore waters of the bay (Figure 3). In May, August, and October, the waters which were not passed by the main sea current were those in the center of the bay (Figure 3).

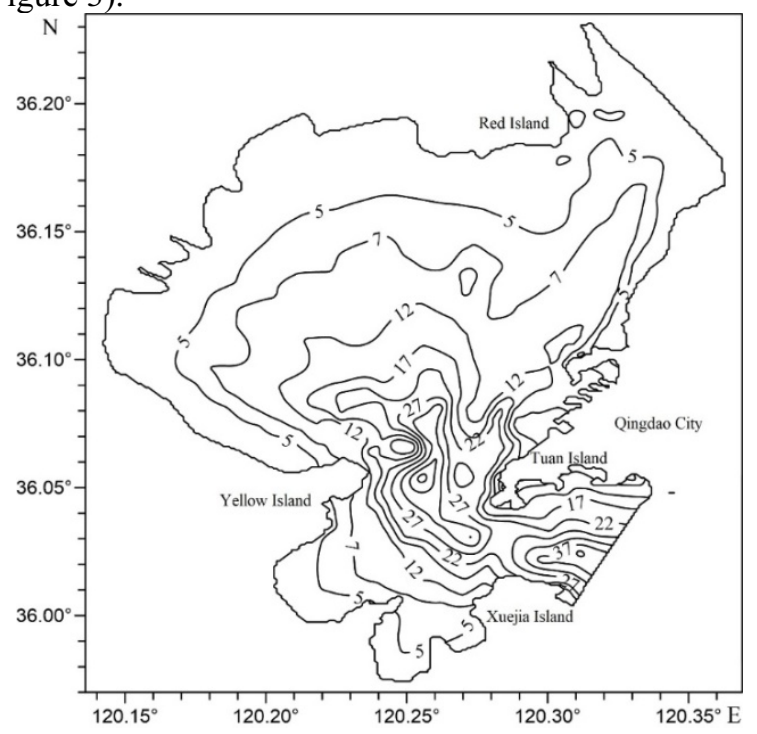

Figure 3 Water depth and topography of Jiaozhou Bay

(m)

The content of $\mathrm{Cd}$ in the lower part of the central water body of Jiaozhou Bay gradually increased from the lowest value of $0.09 \mu \mathrm{g} / \mathrm{L}$ in bottom waters in May. In August, Cd content hit a high of $1.08 \mu \mathrm{g} / \mathrm{L}$ and then began to decline. In October, $\mathrm{Cd}$ content fell to $0.37 \mu \mathrm{g} / \mathrm{L}$. Therefore, $\mathrm{Cd}$ content in bottom waters changed from low to high in May, October and August.

Therefore, the $\mathrm{Cd}$ content in the central surface waters of Jiaozhou Bay from May to October changed from low to high in August, May and October. The change of $\mathrm{Cd}$ content in the bottom layer from low to high was: May, October and August. The change of $\mathrm{Cd}$ content transported by the main sea current from low to high was October, May and August. This indicates that in the central waters of Jiaozhou Bay, the monthly changes of $\mathrm{Cd}$ content in the surface layer and bottom layer were different from those of $\mathrm{Cd}$ content carried by the main sea current and bay current (Table 1).

Table 1 Monthly changes of $\mathrm{Cd}$ content from low to high in different locations in the central waters of the Bay

\begin{tabular}{|c|c|c|c|}
\hline $\begin{array}{c}\text { Locations of Cd } \\
\text { content }\end{array}$ & \multicolumn{2}{|c|}{$\begin{array}{c}\text { Seasonal variation of Cd content } \\
\text { from low to high }\end{array}$} \\
\hline $\begin{array}{c}\text { Cd content } \\
\text { transported by the } \\
\text { main sea current }\end{array}$ & October & May & August \\
\hline $\begin{array}{c}\text { Cd content } \\
\text { transported by the } \\
\text { bay current }\end{array}$ & October & August & May \\
\hline
\end{tabular}

\begin{tabular}{|c|c|c|c|}
\hline $\begin{array}{c}\text { Cd content of the } \\
\text { surface layer }\end{array}$ & August & May & October \\
\hline $\begin{array}{c}\text { Cd content of the } \\
\text { bottom layer }\end{array}$ & May & October & August \\
\hline
\end{tabular}

According to the effect theory of vertical water body, horizontal water body and water [12-14], Cd content rapidly and continuously sinks to the seabed. $\mathrm{Cd}$ content on the surface reaches the bottom, obtaining the cumulative effect and dilution effect. But in the central waters of Jiaozhou Bay, the monthly changes of $\mathrm{Cd}$ content in the surface and the bottom showed different results. Monthly change in Cd content at the bottom was not affected by that in $\mathrm{Cd}$ content at the surface, nor was affected by that in $\mathrm{Cd}$ content transported by the main sea current. It was not affected by monthly changes in $\mathrm{Cd}$ content transported by the bay current either. Therefore, we need to further discuss and study where the monthly change of Cd content at the bottom was affected.

\section{Discussion}

4.1 Sedimentation Process. Through vertical water [14-16], Cd fell to the sea floor after passing through the water. $\mathrm{Cd}$ ions are highly hydrophilic and readily combine with phytoplankton and particles in seawater. In the summer, marine life proliferates[8], increasing rapidly. At the same time, summer is also a wet season, river carries the most suspended particulates. In this way, a large number of suspended particles form a gel on the surface under the propagation of many plankton. At this time, the adsorption capacity of suspended particles is the strongest, absorbing a large number of $\mathrm{Cd}$ ions and bringing them to the surface of the water. Due to gravity and water flow, $\mathrm{Cd}$ content continuously sinks to the seabed [1-12]. Therefore, the continuous settlement from surface water to the seabed is a process of Cd settlement and migration.

4.2 Settlement Process in the Center of the Bay. In May, August and October, water bodies that are not passed by the main sea current are those at site 55 in the center of the bay.

In the central waters of Jiaozhou Bay, the monthly changes of $\mathrm{Cd}$ content in surface and bottom waters were different from those $\mathrm{Cd}$ content transported by the main sea current and the bay current. The monthly variation of $\mathrm{Cd}$ content on the surface and bottom of Jiaozhou Bay showed different results. Then, how the monthly changes of $\mathrm{Cd}$ content in the surface and bottom of the central waters of Jiaozhou Bay were affected by those of $\mathrm{Cd}$ content in the main sea current transport and bay current transport.

Therefore, not only the $\mathrm{Cd}$ content transported by the main sea current into Jiaozhou Bay should be considered, but also the main sea current carrying $\mathrm{Cd}$ content in the waters around Jiaozhou Bay.

The main sea current passed through the bay mouth and flowed along the coastal waters of Jiaozhou Bay at sites 52, 53, 54, 56, 57, 58, 59, 60, 61, 2104, 2105 and 2106 , bringing high $\mathrm{Cd}$ content to the coastal waters of 
Jiaozhou Bay (Figure 2). When the main sea current flowed along the coastal waters of Jiaozhou Bay, the authors call it the bay current.

In May, the main sea current brought a low $\mathrm{Cd}$ content of $0.59 \mu \mathrm{g} / \mathrm{L}$ to Jiaozhou Bay and surrounded the inshore waters of the bay. The baycurrent carried a high Cd content of $0.59-1.53 \mu \mathrm{g} / \mathrm{L}$ which was transported by 4 rivers and run-off in the north to a ring of the near shore surface water. The $\mathrm{Cd}$ content in the central surface water of Jiaozhou Bay was relatively low, which was $0.44 \mu \mathrm{g} / \mathrm{L}$. This means that the baycurrent carrying a high content of $\mathrm{Cd}$ around the surrounding waters of Jiaozhou Bay did not affect the surface water in the center of the bay. Meanwhile, Cd content in the bottom water of Jiaozhou Bay was lower $0.09 \mu \mathrm{g} / \mathrm{L}$. This indicates that the $\mathrm{Cd}$ content in the baycurrentdid not affect the bottom water in the center of Jiaozhou Bay either.

In August, the main sea current brought $\mathrm{Cd}$ content as high as $1.11 \mu \mathrm{g} / \mathrm{L}$. The bay current brought a high $\mathrm{Cd}$ content region of $0.96-1.11 \mu \mathrm{g} / \mathrm{L}$ to the coastal waters. The Cd content in the central surface water of Jiaozhou Bay further decreased to $0.12 \mu \mathrm{g} / \mathrm{L}$. This indicates that the bay current continued to carry high content of $\mathrm{Cd}$ in the coastal waters of the bay from May to August, without affecting the surface water in the center of Jiaozhou Bay. However, $\mathrm{Cd}$ content in the bottom water of central Jiaozhou Bay increased rapidly, with the maximum value of $1.08 \mu \mathrm{g} / \mathrm{L}$. This indicates that from May to August, Haibo River, Licun River, Loushan River, the run-off in the north of the bay and Dagu River transported a large amount of $\mathrm{Cd}$ with a content of $1.07-1.53 \mu \mathrm{g} / \mathrm{L}$ to the bay current while encircling the inner ring of nearshore waters. Thus, the bay current had a great impact on the bottom water in the center of Jiaozhou Bay.

In October, $\mathrm{Cd}$ content in the main sea current began to decrease significantly by $0.39 \mu \mathrm{g} / \mathrm{L}$. The bay current brought a high $\mathrm{Cd}$ content of $0.39-1.10 \mu \mathrm{g} / \mathrm{L}$ to the inshore waters within the bay. Yet in the surface center water of Jiaozhou Bay, Cd content began to rise, reaching $0.89 \mu \mathrm{g} / \mathrm{L}$. This suggests that from August to October, the high content of $\mathrm{Cd}$ carried by the main sea current began to decline significantly. The main sea current rotated around the inshore water but did not affect the surface water in the center of Jiaozhou Bay. However, Cd content in the bottom water of central Jiaozhou Bay began to decrease significantly, reaching a low level of $0.37 \mu \mathrm{g} / \mathrm{L}$. This suggests that from August to October, the high content of $\mathrm{Cd}$ carried by the main sea current began to decline significantly. At the same time, only Licun River and Loushan River transported 1.04-1.10 $\mu \mathrm{g} / \mathrm{L} \mathrm{Cd}$ to the main sea current when the current surrounded the waters of Jiaozhou Bay, which had a certain influence on the bottom water in the center of Jiaozhou Bay.

\subsection{Principle of Monthly Change of Cd Content in Bay} Center. In May, the main sea current carrying high content of $\mathrm{Cd} 0.59-1.53 \mu \mathrm{g} / \mathrm{L}$ surrounded the surface inshore waters of the bay. Then, through the continuous deposition of $\mathrm{Cd}$ content to the seabed, the coastal waters around the bay became the area with high $\mathrm{Cd}$ content $0.09-0.72 \mu \mathrm{g} / \mathrm{L}$. However, this has no effect on the surface water in the center of Jiaozhou Bay, with a low $\mathrm{Cd}$ content of $0.44 \mu \mathrm{g} / \mathrm{L}$. It also had no effect on the bottom water in the center of Jiaozhou Bay, with a lower $\mathrm{Cd}$ content of $0.09 \mu \mathrm{g} / \mathrm{L}$ (Figure 4).

From May to August, according to the effect theory of vertical water body, horizontal water body and water body [12-14], Cd changed greatly after passing through water body through the effect of vertical water body [10-12]. Cd ions are highly hydrophilic and readily combine with phytoplankton and particles in seawater. In the summer, marine life proliferated[8], increasing rapidly. Suspended particles formed colloids on the surface as a result of plankton reproduction. At this point, the adsorption capacity was the strongest, absorbing a large number of $\mathrm{Cd}$ ions and bringing them into surface water. Due to gravity and tide, Cd content continuously sank to the seabed [1-6]. Jiaozhou Bay is a dustpan shaped shallow bay with a straight slope. It turns to slope to the east at the bay mouth. The water is shallow in the northwest and deep in the southeast (Figure 3). The average depth of the bay is $7.0 \mathrm{~m}$. The maximum water depth is near the bay mouth, up to $64 \mathrm{~m}$ in some places. And that in the water inside the bay is $51 \mathrm{~m}$ (Figure 3). As a result, Cd content constantly sinking to the seabed gradually moved along the offshore sea floor to the central bottom of the bay under the influence of gravity and tidal currents. In this way, from May to August, Cd content sinking to the seabed migrated from the bottom of the bay to the bottom center of the bay, forming a high $\mathrm{Cd}$ area of $1.08 \mu \mathrm{g} / \mathrm{L}$ and a low Cd area of $0.08-0.24 \mu \mathrm{g} / \mathrm{L}$ at the lower inshore waters surrounding a circle of the bay (Figure 5). Meanwhile, Cd content in the central surface water of Jiaozhou Bay further decreased to $0.12 \mu \mathrm{g} / \mathrm{L}$.

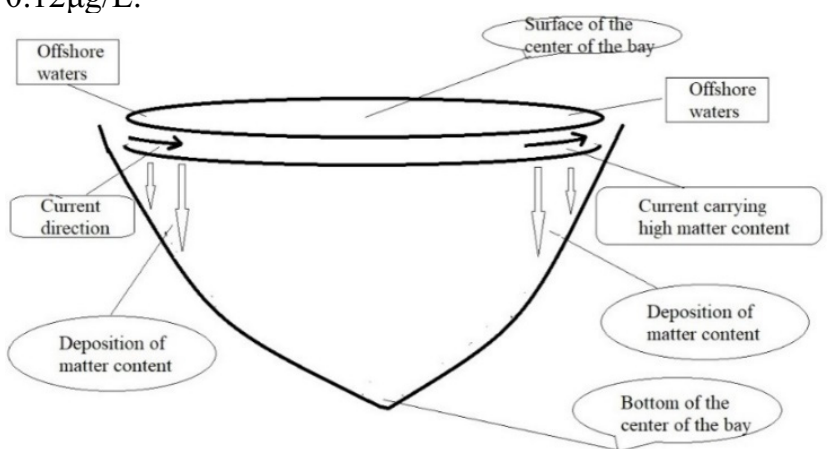

Figure 4 The main sea current carrying high matter content in Jiaozhou Bay

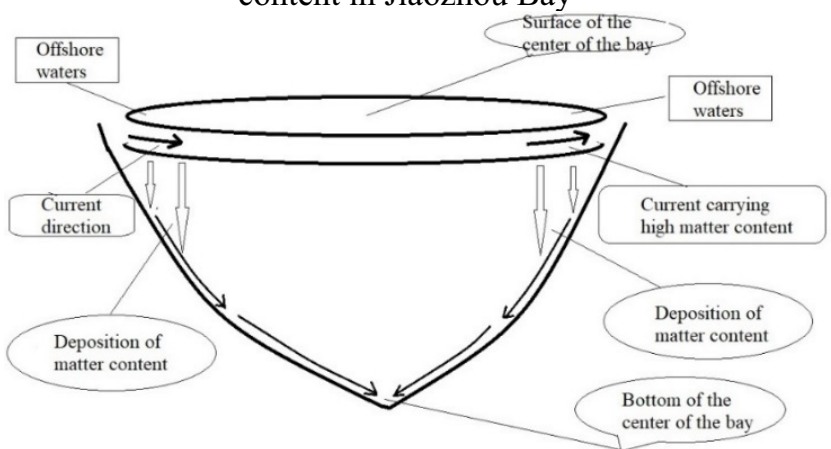

Figure 5 The main sea current carrying deposition of high matter content in Jiaozhou Bay

Therefore, from May to August, the main sea current continued to carry high content of $\mathrm{Cd}$ surrounding the coastal water body in Jiaozhou Bay, which had no 
influence on the central surface water body, but had great influence on the central bottom water body.

From August to October, the high $\mathrm{Cd}$ content transported by the main sea current began to drop significantly to $0.39 \mu \mathrm{g} / \mathrm{L}$. At this time, the main sea current flowed into Jiaozhou Bay and encircled inshore water within the bay. Only two rivers transported $\mathrm{Cd}$ content to the bay. The high Cd content of $0.39-1.10 \mu \mathrm{g} / \mathrm{L}$ carried by the bay current was transported to the near shore surface water area. The main sea current, source transport and bay current greatly reduced the $\mathrm{Cd}$ content, which had great influence on the bottom water in the center of Jiaozhou Bay. The high content of $\mathrm{Cd}$ at the bottom of the bay also decreased significantly to a low value of $0.37 \mu \mathrm{g} / \mathrm{L}$.

From August to October, a small amount of $\mathrm{Cd}$ deposited and accumulated in the center of the bottom of the bay, forming a $0.37 \mu \mathrm{g} / \mathrm{L}$ low-Cd region. At this time, a high $\mathrm{Cd}$ content zone of $1.08 \mu \mathrm{g} / \mathrm{L}$ was formed at the central bottom of the bay. Therefore, in the bottom water in the center of the bay, the high $\mathrm{Cd}$ content began to rise to the surface water, increasing $\mathrm{Cd}$ content in the surface water. This suggests that surface water in the center of the bay was influenced by bottom water. From August to October, high $\mathrm{Cd}$ content in the bottom water of the bay gradually rose to the surface water and continued to exert an influence on the surface water. Thus, $\mathrm{Cd}$ content gradually increased in October, reaching a high level of $0.89 \mu \mathrm{g} / \mathrm{L}$ (Figure 6).

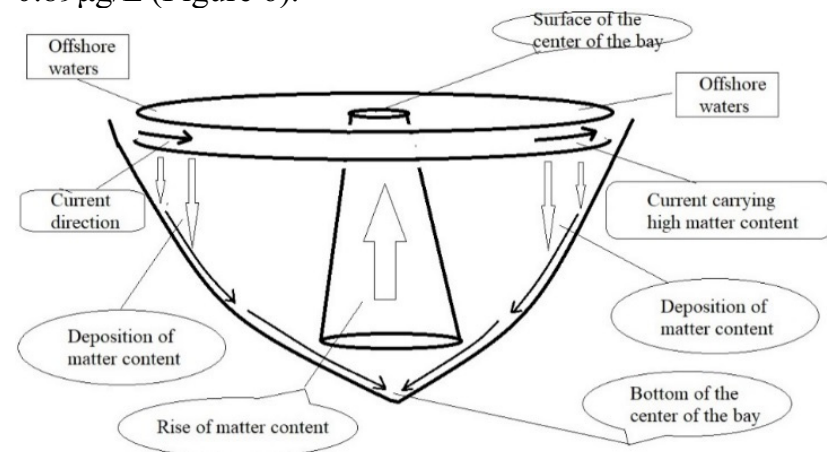

Figure 6 Deposition and rise of high matter content carried by the main sea current in Jiaozhou Bay

The monthly variation of $\mathrm{Cd}$ content in the center of the bay confirmed the migration rule of matter content proposed by the authors. Matter content migration mechanism in Jiaozhou Bay was proposed: 1) the main sea current carrying high matter content surrounded coastal waters of the bay. 2) In inshore areas around the bay, high matter content which was deposited to the seabed migrated into the center of the bottom of the bay, forming a high matter content area at the bottom of the center bay. 3) In bottom water in the center of the bay, high matter content rose to the surface of water, increasing the matter content in the surface water. The model block diagrams (Figure 4, Figure 5 and Figure 6) were established to show the mechanism and change process of matter content migration.

\section{Conclusion}

The main sea current passed through the bay mouth and entered into Jiaozhou Bay along a ring of nearshore waters, bringing high $\mathrm{Cd}$ content. When the main sea current surrounded the inshore waters of Jiaozhou Bay, it is called the baycurrent.In May, August, and October, the waters that were not passed by the main sea currentwere in the center of the baywhere site 55 lies.Cd content in central surface water of Jiaozhou Bay was not transported from any source outside the bay between May and October.

In May, $\mathrm{Cd}$ content transported by the main sea current was $0.59 \mu \mathrm{g} / \mathrm{L}$. Cd content in the main sea current transport in August was $1.11 \mu \mathrm{g} / \mathrm{L}$. Cd content transported by the main sea current in October was $0.39 \mu \mathrm{g} / \mathrm{L}$. The change of $\mathrm{Cd}$ content in the main sea current transport from low to high was October, May and August.

In May, $\mathrm{Cd}$ content in the bay current ranged from 0.59 to $1.53 \mu \mathrm{g} / \mathrm{L}$. In August, $\mathrm{Cd}$ content carried by the bay current changed from $0.96 \mu \mathrm{g} / \mathrm{L}$ to $1.11 \mu \mathrm{g} / \mathrm{L}$. In October, $\mathrm{Cd}$ content in the bay current varied from 0.39 to $1.10 \mu \mathrm{g} / \mathrm{L}$. The $\mathrm{Cd}$ content transported bay current varied from low to high in October, August, and May.

In the surface waters of central Jiaozhou Bay, Cd content began to be as low as $0.44 \mu \mathrm{g} / \mathrm{L}$ in May. In August, $\mathrm{Cd}$ content hit a low of $0.12 \mu \mathrm{g} / \mathrm{L}$. In October, Cd content reached a high value of $0.89 \mu \mathrm{g} / \mathrm{L}$. The surface $\mathrm{Cd}$ content changed from low to high in August, May and October.

The $\mathrm{Cd}$ content at the bottom of the central water body of Jiaozhou Bay began to be as low as $0.09 \mu \mathrm{g} / \mathrm{L}$ in May. In August, Cd content hit a high of $1.08 \mu \mathrm{g} / \mathrm{L} . \mathrm{Cd}$ content was low in October, at $0.37 \mu \mathrm{g} / \mathrm{L}$. Therefore, in May, October and August, the bottom Cd content varied from low to high.

Thus, the monthly changes of $\mathrm{Cd}$ content in the surface and bottom of the central waters of Jiaozhou Bay from May to October were different from those of $\mathrm{Cd}$ content carried by the main sea current and bay current.

The changes of $\mathrm{Cd}$ content in the main sea current transport, in bay current transport, in the center surface water and bottom water of Jiaozhou Bay show the monthly change process of Cd content in Jiaozhou Bay. The monthly variation laws of $\mathrm{Cd}$ content in the surface and bottom of bay central waters were proposed, and the block diagram models were established to demonstrate the process and principle of $\mathrm{Cd}$ content deposition and migration. This principle indicates that from May to October, the main sea current continued to carry high $\mathrm{Cd}$ content to the coastal waters of Jiaozhou Bay, forming the bay current which did not directly affect the surface water in the center of Jiaozhou Bay. But it had a great influence on the bottom water in the center of Jiaozhou Bay and further affected the surface water in the center of Jiaozhou Bay through the upwelling.

\section{Acknowledgement}

This research was sponsored by Doctoral Degree Construction Library of Guizhou Nationalities University, Research Projects of Guizhou Nationalities University ([2014]02), Research Projects of Guizhou Province Ministry of Education (KY [2014] 266), Research Projects of Guizhou Province Ministry of Science and Technology (LH [2014] 7376). 


\section{References}

1. Dongfang Yang, Zhenqing Miao. Marine Bay Ecology (Volume 1) [M]. Beijing: China Ocean Press, 2010, 1-320.

2. Dongfang Yang, Zhenhui Gao. Marine Bay Ecology (Volume 2) [M]. Beijing: China Ocean Press, 2010, 1-330.

3. Dongfang Yang, Yu Chen, Hong Wang, Chunru Yang, Junhui Guo. Environmental Background Composition and Transfer Process of Cadmium in Jiaozhou Bay [J]. Coastal Engineering, 2010, 29 (4): 73-82.

4. Dongfang Yang, Yu Chen, Yanxiang Chang, Chunxiu Liu, Yichan Weng. The Source and Distribution of Cadmium in Jiaozhou Bay [J]. Coastal Engineering, 2013, 32 (3): 68-78.

5. Dongfang Yang, Sixi Zhu, Fengyou Wang, Huazhong He and Yunjie $\mathrm{Wu}$. The distribution and content of Cadmium in Jiaozhou Bay [J]. Applied Mechanics and Materials Vols.644-650. 2014, 5325-5328.

6. Dongfang Yang, Sixi Zhu, Xiuqin Yang, Xiaoli Zhao and Fengyou Wang. Pollution level and Sources of $\mathrm{Cd}$ in Jiaozhou Bay [J]. Materials Engineering and Information Technology Application. 2015, 558-561.

7. Dongfang Yang, Fengyou Wang, Xiuqin Yang, Ming Wang, Sixi Zhu. Cadmium background pollution in Jiaozhou Bay $[\mathrm{J}]$. Advances in Engineering Research. 2016, 60: 1347-1350.

8. Dongfang Yang, Sixi Zhu, Zhikang Wang, Xiuqin Yang, Fengyou Wang. Spatial-temporal changes of Cd in Jiaozhou Bay [J]. Computer Life, 2016, 4(5): 446-450.

9. Dongfang Yang, Fengyou Wang, Sixi Zhu, ChunhuaSu and Xiuqin Yang. The influence of river on $\mathrm{Cd}$ contents in Jiaozhou Bay [J]. World Scientific Research Journal, 2017, 3(1): 1-5.

10. Dongfang Yang, Haixia Li, Xiaolong Zhang, Qi Wang, Zhenqing Miao. Spatial-temporal migration laws of Cd in Jiaozhou Bay [J]. Earth and Environment Science, 2018, 113 (012129): 1-4.

11. YANG D F, CHEN Y, GAO Z H, et al. Silicon Limitation on primary production and its destiny in Jiaozhou Bay, China IV transect offshore the coast with estuaries [J]. Chin. J. Oceanol. Limnol. 2005, 23(1): 72-90.

12. Dongfang Yang, Fan Wang, Zhenhui Gao, et al. Ecological Phenomena of Phytoplankton in Jiaozhou Bay [J]. Marine Science, 2004, 28 (6): 71-74.

13. State Oceanic Administration. The Specification for Marine Monitoring [Z]. Beijing: China Ocean Press, 1991.

14. Dongfang Yang, Fengyou Wang, Huozhong He, Sixi Zhu and Yunjie Wu. Vertical water body effect of benzene hexachloride [J]. Proceedings of the 2015 international symposium on computers and informatics. 2015, 2655-2660.
15. Dongfang Yang, Fengyou Wang, Xiaoli Zhao, Yunjie Wu, Sixi Zhu. Horizontal waterbody effect of hexachlorocyclohexane [J]. Sustainable Energy and Environment Protection. 2015, 191-195.

16. Dongfang Yang, Fengyou Wang, Xiuqin Yang, Yunjie Wu and Sixi Zhu. Water's effect of benzene hexachloride [J]. Advances in Computer Science Research. 2015, 2352: 198-204. 